\title{
Facilitating transition of young people with long-term health conditions from children's to adults' healthcare services - implications of a 5-year research programme
}

\author{
Authors: Allan Colver, ${ }^{\mathrm{A}}$ Tim Rapley, ${ }^{\mathrm{B}}$ Jeremy R Parr, ${ }^{\mathrm{C}}$ Helen McConachie, ${ }^{\mathrm{D}}$ Gail Dovey-Pearce, ${ }^{\mathrm{E}}$ Ann Le Couteur, ${ }^{\mathrm{F}}$ \\ Janet E McDonagh, ${ }^{G}$ Caroline Bennett, ${ }^{\mathrm{H}}$ Gregory Maniatopoulos, ${ }^{\mathrm{I}}$ Mark S Pearce, ${ }^{\mathrm{J}}$ Debbie Reape, ${ }^{\mathrm{K}}$ Nichola Chater, ${ }^{\mathrm{L}}$ \\ Helena Gleeson ${ }^{\mathrm{M}}$ and Luke Vale ${ }^{\mathrm{N}}$
}

\section{Background}

During transition from children's to adults' healthcare, young adults with long-term conditions may show delays in psychosocial development compared to their peers without long-term conditions, and deterioration of their conditions' medical control.

Methods

This paper integrates the findings, already published in 10 separate papers, of a 5 -year transition research programme.

Implications

There is an important role for funders (commissioners) of adults' services to fund transitional healthcare, in addition to funders of children's services who currently take responsibility.

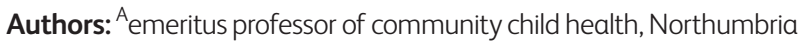
Healthcare NHS Foundation Trust, North Shields, UK and Newcastle University, Newcastle upon Tyne, UK; ${ }^{\text {B }}$ professor of applied health care research, Northumbria University, Newcastle upon Tyne, UK; Cprofessor of paediatric neurodisability, Northumbria Healthcare NHS Foundation Trust, North Shields, UK, Newcastle University, Newcastle upon Tyne, UK and Great North Children's Hospital, Newcastle upon Tyne, UK; ' emeritus professor of child clinical psychology, Newcastle University, Newcastle upon Tyne, UK; ${ }^{E}$ consultant clinical psychologist, Northumbria Healthcare NHS Foundation Trust, North Shields, UK and Newcastle University, Newcastle upon Tyne, UK; F professor of child and adolescent psychiatry, Newcastle University, Newcastle upon Tyne, UK and Tyne and Wear NHS Foundation Trust, Newcastle upon Tyne, UK; ${ }^{G}$ senior lecturer in paediatric and adolescent rheumatology, Centre for Epidemiology Versus Arthritis, Manchester, UK and NIHR Manchester Biomedical Research Centre, Manchester, UK; ${ }^{\mathrm{H}}$ assistant director for social care, Council for Disabled Children, London, UK; I senior research associate in medical sociology, Newcastle University, Newcastle upon Tyne, UK; ' professor of applied epidemiology, Newcastle University, Newcastle upon Tyne, UK; ${ }^{\text {K }}$ deputy director of nursing, Northumbria Healthcare NHS Foundation Trust, North Shields, UK; ' ${ }^{\text {consultant }}$ rehabilitation physician, Tyne and Wear NHS Foundation Trust, Newcastle upon Tyne, UK; ${ }^{\text {M }}$ consultant endocrinologist, University Hospitals Birmingham NHS Foundation Trust, Birmingham, UK;

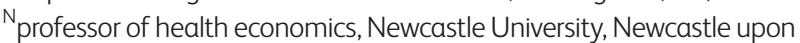
Tyne, UK
It is important that healthcare provider organisations adopt an organisation-wide approach to implementation to ensure that good practice is adopted in children's and adults' services, not just adopted by enthusiasts in some specialties. This includes provision of 'developmentally appropriate healthcare' which recognises the changing biopsychosocial developmental needs of young people.

Three features of transitional healthcare were associated with improved outcomes: appropriate parent involvement, promotion of young people's confidence in managing their health and meeting the adult team before transfer. These should be maintained or introduced as a priority.

Child and adult healthcare providers should routinely explore with a young person how they approach transition and personalise their clinical approach thereafter.

These implications are relevant for a range of stakeholders, including funders of transitional healthcare, organisations providing transitional healthcare and clinical practitioners.

KEYWORDS: Transition to adult care, quality of life, young adult, type 1 diabetes mellitus, cerebral palsy

\section{Introduction}

In this article we present the implications of a recently completed 5-year programme of applied health research on transition, funded by the UK National Institute for Health Research (NIHR). Most of our results are available in other peer-reviewed papers; this paper integrates these interlinked studies to provide a synthesis not accessible from the papers in isolation.

Clinical care requires funding and managerial support in order to bring about change. Therefore, our research programme adopted a comprehensive approach, covering funding (commissioning), provision by healthcare organisations and clinical care. We use the word 'funding' as well as 'commissioning' for those readers not familiar with the commissioning environment of the UK NHS. Before our work, no research had been undertaken on commissioning for transition.

The UK's royal colleges of physicians and Royal College of Paediatrics and Child Health recognise the need for clinicians to 
Box 1. Summary of the methods used in the nine interlinked studies

1a A Young People's Advisory Group (UP) was formed at the outset of the research programme and met monthly over 5 years.

1b A project designed and co-led by UP explored the usefulness of patient-held health information. Young people with long-term conditions were asked to examine examples of health passports and to complete a questionnaire about them.

1c A 'Q-sort' study was undertaken to explore the importance young people attached to different elements of transitional healthcare.

2a We conducted a longitudinal study of 374 young people with one of three exemplar long-term conditions (type 1 diabetes, cerebral palsy or autism spectrum disorder (ASD) with an associated mental health problem) to assess whether nine proposed beneficial features of transition services contributed to improved outcomes. Each young person was visited by research assistants four times, 1 year apart. Outcomes were participation, wellbeing, satisfaction with services and condition-specific measures. Young people with diabetes were recruited from five UK healthcare provider organisations at different stages of development of transitional healthcare; young people with ASD were recruited from four healthcare provider organisations, two with an adult service to which to transfer young people; and young people with cerebral palsy were recruited from two regional population registers, care being provided by 17 provider organisations.

$2 \mathrm{~b}$ A qualitative study was completed with a sub-sample of 13 young people, their families and healthcare professionals to investigate experiences of transition. It used in-depth interviews and observations of clinical consultations.

2c A discrete choice experiment was undertaken. Also, an estimation of healthcare costs, assessment of health-related quality of life (EQ-5D-Y questionnaire) and Markhov economic modelling of cost-effectiveness of illustrative models of transition.

3a An ethnographic study in three UK hospitals was undertaken to identify factors enabling or inhibiting the introduction of developmentally appropriate healthcare (DAH). We then compiled a toolkit to assist introduction of DAH.

3b The research focusing on healthcare funders included a literature review, in-depth interviews and site visits to understand what information UK healthcare funders use to inform their understanding about purchasing for effective transition.

3c Meetings were undertaken with healthcare funders to synthesise learning from the programme about 'what' to fund.

promote better transitional healthcare and for training to include transitional healthcare. ${ }^{1-3}$

\section{Importance of transition}

During transition from child-centred to adult-oriented healthcare, young people with long-term conditions may show delays in autonomy, psychosexual and social development compared to their peers without long-term conditions, as well as poor medical control of their condition, for example, in individuals with diabetes, $\mathrm{HbA} 1 \mathrm{c}$ may rise during adolescence. ${ }^{4-8}$ Disabling conditions such as cerebral palsy give rise to symptoms including pain and spasticity which may not be adequately addressed during transition. ${ }^{9}$ Few young adults with neurodevelopmental disorders such as autism spectrum disorder (ASD) attain their potential for employment, relationships and participation in society. ${ }^{10,11}$ Such problems are recognised internationally. ${ }^{12-14}$

Transition is defined as 'the purposeful, planned process that addresses the medical, psychosocial, educational and vocational needs of adolescents and young adults with chronic medical and physical conditions as they move from child-centred to adult-oriented healthcare systems'. ${ }^{15}$ Transfer is the event when responsibility for healthcare is passed from a child health provider to an adult health provider. 'Young person' refers to individuals aged $10-24$ years. ${ }^{16}$

In the UK, and other countries, much transitional healthcare is considered sub-optimal despite guidance being in place for at least 15 years. 17,18 The UK and Australia are the only high income countries with national guidance on transition, though several academies and specialty groups in other countries have published recommendations. ${ }^{14,19,20}$

There is a little firm evidence to inform decisions about how to improve transitional healthcare. While some small studies have shown improvements following locally designed interventions, these are difficult to generalise from because evaluation was usually by those who introduced the intervention, most used a retrospective uncontrolled before-and-after study design rather than prospective, and few showed that their interventions were sustained or sustainable. ${ }^{21,22}$

\section{Purpose and objectives of the research programme}

The purpose of the Transition research programme was to promote the subjective wellbeing and health of young people with long-term conditions by generating evidence to enable healthcare funders and healthcare providers to facilitate successful transition.

The programme had three objectives.

$>$ To work with young people with long-term conditions to determine what successful transition means to them and what is important in their transitional healthcare.

> To identify features of transitional healthcare that are effective and efficient.

> To determine how transitional healthcare should be funded and provided.

\section{Methods}

Box 1 provides a summary of the methods used for the nine interlinked studies that addressed the three programme objectives.

\section{Ethics committee opinion and consent to participate}

The interlinked studies received favourable ethics opinions from Newcastle and North Tyneside Research Ethics Committee, numbers 12/NE/0059, 12/NE/0206, 12/NE/0284 and 12/NE/0423. All participants gave informed, verbal and written consent to join the studies. 
Box 2. Implications of the research programme

There is an important role for funders (commissioners) of adult services to fund transitional healthcare, in addition to funders of child services with whom that responsibility currently lies.

Our findings indicate the importance of healthcare services being commissioned to ensure providers deliver developmentally appropriate healthcare across all healthcare services, and that this will be facilitated by commitment from senior provider and commissioner leaders.

It is important that healthcare provider organisations adopt an organisation-wide approach to implementation of better transitional healthcare. Establishing a transition steering committee, chaired by an organisation-wide 'transition coordinator', will facilitate this.

Joint planning between adult and child healthcare providers, and primary care, is likely to improve both transfer of individual young people and adoption of ways of working which improve the healthcare of this population.

Three features of transitional healthcare were associated with improved outcomes: appropriate parent involvement, promotion of young people's confidence in managing their health condition and wider health (health self-efficacy), and meeting the adult team before transfer. Consideration should be given to maintaining or introducing these as a priority.

Child and adult healthcare providers should routinely explore with a young person how they approach transition and personalise their clinical approach thereafter.

Maximal service uptake would be achieved if services encouraged parental involvement, ensured staff continuity and encouraged young people to make decisions about their care.

\section{Implications of the research programme}

A summary of the seven key implications is shown in Box 2 and the evidence for each is discussed.

> There is an important role for funders (commissioners) of adult services to fund transitional healthcare, in addition to funders of child services with whom that responsibility currently lies.

In our interviews with representatives of local and national funding (commissioning) organisations (Box 1 points $3 \mathrm{~b}$ and c), work packages 3.2 and 3.3 in the final report, healthcare transition was often not regarded as a priority and the process was not usually monitored by healthcare funders or providers. ${ }^{23}$ Further, there was the expectation from funders and providers of adult services that transition was the responsibility of child services to improve. This is not appropriate, as transition continues after transfer to adult care into the patients' mid-twenties. Appropriate provision by the receiving service is as important as preparation provided by the transferring service. This requires taking an integrated approach within health and between health and social care. ${ }^{24}$

$>$ Our findings indicate the importance of healthcare services being commissioned to ensure providers deliver 'developmentally appropriate healthcare' (DAH) across all healthcare services, and that this will be facilitated by commitment from senior provider and commissioner leaders.

Transitional healthcare should be in the context of healthcare provided for all young people. ${ }^{25}$ Recent advances in neuroimaging indicate that the brains of young people change considerably between 10 and 24 years of age. ${ }^{26}$ In this context, an important concept relevant to all healthcare services for young people, and especially for those in transition, is DAH. We identified five dimensions which led to a working definition of DAH. ${ }^{27,28}$

$D A H$ recognises the changing biopsychosocial developmental needs of young people and the need to empower young people by embedding health education and health promotion in consultations. In operational terms, DAH focuses on the approach of healthcare professionals to the engagement of each young person and their parents, alongside the structure of the organisations in which care takes place. ${ }^{29}$

DAH provides bridging and continuity across adolescent, young adult and adult care and its characteristics are shown in Table 1.

Qualitative work undertaken in three hospitals (Box 1 point 3a) identified several organisational barriers to introducing DAH: no single group in the hospitals took responsibility for delivering services for young people; there was perceived (incorrectly) to be few young people attending hospital; the mind-set and skill-set of many staff were often not ready to introduce DAH; and good practices led by enthusiasts in one child health setting rarely generalised to other child health settings or adult services. Organisational solutions to introducing DAH across an entire healthcare organisation were formal support for DAH at senior executive and board level; planning which engages senior managers in both adult and child services from the outset; and an organisation-wide strategy for training in DAH.

A toolkit to assist professionals with the introduction of DAH was developed by the multidisciplinary clinical research team within our programme. ${ }^{29,31}$

> It is important that healthcare provider organisations adopt an organisation-wide approach to implementation of better transitional healthcare. Establishing a transition steering committee, chaired by an organisation-wide 'transition coordinator', will facilitate this.

We found (Box 1 point 3a) that similar organisational barriers to introducing DAH applied to wider aspects of transitional healthcare. Where a hospital had identified a transition coordinator, we found there was a coherent approach to introducing transitional healthcare across all specialties and in adult and child services, and that the need for training was recognised.

> Joint planning between adult and child healthcare providers, and with primary care, is likely to improve both transfer of individual young people and adoption of ways of working which improve the healthcare of this population. 
Table 1. Examples of how the five conceptual dimensions of developmentally appropriate healthcare can be translated into practice ${ }^{27}$

\begin{tabular}{|c|c|}
\hline Dimension of DAH & Translation into practice \\
\hline \multirow{3}{*}{$\begin{array}{l}\text { Biopsychosocial } \\
\text { development and holistic } \\
\text { care }\end{array}$} & $\begin{array}{l}\text { > Undertake biopsychosocial developmental assessment, with approach to the young person adjusted } \\
\text { accordingly (see Box } 1 \text { and Farre and McDonagh). }{ }^{30}\end{array}$ \\
\hline & $\begin{array}{l}\text { Be approachable and welcoming. In general, adolescents appreciate friendliness, with much facial } \\
\text { expression. }\end{array}$ \\
\hline & $\begin{array}{l}\text { Use a psychosocial screening questionnaire such as HEEADSSS (home environment, education/ } \\
\text { employment, eating, activities, drugs, sexuality, suicidal ideation, safety). }\end{array}$ \\
\hline \multirow{4}{*}{$\begin{array}{l}\text { Acknowledgement of } \\
\text { young people as a distinct } \\
\text { group }\end{array}$} & > Explain confidentiality and rights. \\
\hline & > Provide opportunity to consult with young person alone. \\
\hline & $>$ Arrange flexible access to services (eg after school or college). \\
\hline & > Arrange dedicated clinics and space, with appropriate magazines etc. \\
\hline \multirow{3}{*}{$\begin{array}{l}\text { Adjustment of care as the } \\
\text { young person develops }\end{array}$} & > Adjust communication style in line with cognitive development. \\
\hline & > Assess impact of physical growth and puberty on condition and therapy. \\
\hline & > Facilitate graded opportunities to develop self-management skills. \\
\hline \multirow{2}{*}{$\begin{array}{l}\text { Empowerment of } \\
\text { the young person by } \\
\text { embedding health } \\
\text { education and health } \\
\text { promotion }\end{array}$} & $\begin{array}{l}\text { Support the family as it moves from shared care to self-management by the young person of their } \\
\text { healthcare and navigation of healthcare services. }\end{array}$ \\
\hline & > Provide information on what to expect from healthcare services during transition. \\
\hline \multirow{2}{*}{$\begin{array}{l}\text { Interdisciplinary and } \\
\text { interorganisational work }\end{array}$} & > Arrange staff training across the organisation in adolescent health and DAH. \\
\hline & > Ensure adolescent and young adult issues are addressed in policies and guidelines. \\
\hline
\end{tabular}

Across our interlinked studies, we found little evidence that primary care (family practitioners or general practitioners (GPs)) were jointly involved in transitional healthcare planning for young people attending specialist hospital-based children's services. Family practitioners should be kept better informed by hospital services about a young person's management, especially once the individual has reached the age of about 12 years as this represents an age around the time of early adolescence, following the move to secondary schooling, when young people are exploring and becoming more independent in different aspects of their lives. Therefore, understanding how to access primary care and the role of their GP in their health at this time would be invaluable both for the young person who may want to access their advice independently and for the GP understanding the young person in the context of their long-term condition. If there is no adult secondary care service to transfer to, then there should be a formal transfer to primary care, with appropriate documentation and assistance to the young person to make their first appointment.

> Three features of transitional healthcare were associated with improved outcomes: appropriate parent involvement, promotion of young people's confidence in managing their health condition and wider health (health self-efficacy), and meeting the adult team before transfer. Consideration should be given to maintaining or introducing these as a priority.

We had identified nine features of transitional healthcare for which there was preliminary evidence from small studies that they might improve outcomes. ${ }^{32}$ We examined the associations of provision of each feature with outcomes for young people who were attending healthcare provider organisations in the 3-year longitudinal study of 374 young people with long-term conditions (Box 1 point $2 a$ ). ${ }^{33}$

For six of the nine features, there was no association with improved outcomes: having a key worker, having access to holistic life-skills training, having a written transition plan, having a coordinated team, age-banded clinic and having a transition manager working in a clinical team. ${ }^{33}$ For three features (Box 3), we found association with improved clinical outcomes of participation, wellbeing, satisfaction with services and conditionspecific measures (Box 1 point 2a). ${ }^{33}$

Appropriate parent involvement

> Findings from our qualitative work (Box 1 point 2b) confirmed how important parents were to the process of transition. ${ }^{34}$ Allen's study of young people with diabetes in transition emphasised the importance of parents during transition. ${ }^{35}$ A systematic review of studies of parents' perceptions of their role in transition concluded that 'Parents can be key facilitators of their child's healthcare transition, supporting them to become experts in their own care.' 36

Promotion of health self-efficacy

> Findings from our qualitative work (Box 1 point 2b) revealed that both parents and young people thought this was a central element of transitional healthcare. ${ }^{34}$ This qualitative work also found that health self-efficacy required learning how to manage one's healthcare needs and how to navigate healthcare services.

$>$ 'Continuing attention to self-management' was associated with better health-related quality of life. ${ }^{37}$ However, further work is needed to identify the most effective and efficient ways to promote young people's knowledge and confidence in the 
Box 3. Descriptions of the three features of transitional healthcare associated with improved outcomes

\begin{abstract}
Appropriate parent involvement in their child's care, but with changing responsibilities
Parent and young person are asked separately if they think the level of involvement is appropriate. Involvement concerns what happens in the clinic (parent being present or not and who does the talking) and also discussions at home about the young person's health and how to manage it. This needs to be in the context of informing both parent and young person, when developmentally appropriate, of the right of the young person to be seen independently of their parent if they choose.
\end{abstract}

\title{
Promotion of health self-efficacy
}

The clinic has a written policy about how it encourages the young person to take responsibility for their health and gives them information about their condition and appropriate skills training.

\section{Meet adult team before transfer}

This could be in a joint clinic where senior child and adult clinicians consult together; or the adult clinician might visit the child clinic to be introduced; or the young person might be taken to the adult clinic by a member of the child team to meet the adult team.

management of their long-term condition and overall health and so improve health self-efficacy. ${ }^{38}$

Meeting the adult team before transfer

> Qualitative work (Box 1 point 2b) highlighted the benefit for young people and parents of meeting the adult team before transfer but also some of the practical difficulties of trying to organise such meetings, for example, the young person might meet someone who was subsequently not responsible for their care; or they could not attend if an opportunity was only offered once a year. ${ }^{34}$ Other studies find that arrangements, such as joint clinics, show improvements in process indicators - for example following renal transplant. ${ }^{39}$

These three features of transitional healthcare (Box 3) were found to be associated with better clinical outcomes, likely to offer value for money and a positive return on investment. This follows from the work of Box 1 point 2c and is reported in Appendix 7 of the final report. ${ }^{23}$

Resources (which includes training) should therefore be directed first to embedding into service provision the three features for which we found convincing evidence of benefit, within organisation-wide provision of DAH as discussed previously.

> Child and adult healthcare providers should routinely explore with a young person how they approach transition and personalise their clinical approach thereafter.

A 'Q-sort' study (Box 1 point 1c) with young people attending clinics for a range of long-term conditions identified four interaction styles that young people adopted when approaching their transition: laid back, anxious, wanting autonomy and socially oriented (welcoming support from, and frequent discussions with, family, friends and healthcare professionals). ${ }^{40}$ Discussing with young people their approach to transition is likely to help clinicians and young people develop personalised plans to maximise engagement and retention in services. However, clinicians should bear in mind that such preferences may change over time.

> Maximal service uptake would be likely to be achieved if services encouraged parental involvement, ensured staff continuity and encouraged young people to make decisions about their care.

Experts in the field consider that retaining young people in specialist care, before and after transfer, is a key indicator of better outcomes. ${ }^{41}$ Using a discrete choice experiment (an economics technique for eliciting the preferences individuals have for various combinations of attributes being studied), we found that the above attributes (achieved if services encouraged parental involvement, ensured staff continuity and encouraged young people to make decisions about their care) were highly valued by young people and would incline them to continue to attend the clinics (Box 1 point 2c); Appendix 7 of the final report. $^{23}$

\section{Strengths and limitations}

We have focused on experience of care, health of the specific population and cost of care as recommended by the US triple aim framework. ${ }^{42}$ Further, we examined arrangements for funding and providing transitional healthcare in the UK.

We did not postulate an ideal 'service' arrangement, and we have not evaluated a specific model of healthcare provision. Rather, in a hypothesis driven longitudinal observational study (Box 1 point $2 a$ ), we examined the associations of nine predetermined features of transitional healthcare with the predetermined outcomes of satisfaction with services, participation (as defined by the International Classification of Functioning, Disability and Health) and wellbeing. ${ }^{43}$ Wellbeing, in particular, has not been captured in evaluative studies of transition, but it is increasingly recognised to be an important healthcare outcome. ${ }^{44,45}$

Our programme of research aimed to identify generic features of transitional healthcare that are relevant to young people with a wide range of long-term conditions. The technical aspects of how, for example, insulin administration, monitoring of cardiac status or spasticity management should be adjusted between ages 12 and 24 years, remain rightly the domain of specialty groups. However, research by these groups investigating why transition may not go well often finds that the problems lie with the generic issues our research addressed, rather than the technical aspects relevant to individual conditions. ${ }^{46,47}$

Regarding limitations, we did not examine the role of primary care (family physicians) and we did not study longer-term outcomes after patient age of 23 years. Further, our research was directed to investigating how to improve transitional healthcare, but we appreciate that young people and their families are likely to engage with a broader range of educational, occupational and social care providers working in collaboration with healthcare services. 


\section{How generalisable are our findings?}

This is the largest study to examine transition longitudinally and to collect hypothesis-driven data from young people at home visits (compared to data-linkage studies from administrative datasets). The results may be generalisable to other long-term conditions because the three conditions (diabetes, cerebral palsy and ASD with associated mental health problem) were deliberately chosen to include individuals that varied considerably in their healthcare needs, psychosocial complexity and availability of adult services. We recruited from all young people with cerebral palsy in two population registers (looked after in 17 healthcare organisations) and all young people with diabetes or ASD with associated mental health problem in nine secondary care provider organisations widely distributed across the UK (in the UK, all such young people are seen in secondary care). Thus, complete populations of individuals with one of the three conditions were sampled from.

The 374 participants did not differ significantly from those declining to take part. The distribution of severity of the three conditions was similar to that in national samples. Attrition did not appear to create bias as there were no significant differences between those remaining and not remaining in the study with respect to sex, age, condition, diabetes site or ASD site. ${ }^{33}$ Thus, we think that the non-participation and attrition in our study did not adversely affect the representativeness of those we aimed to recruit.

The results may be generalisable to other healthcare provider organisations because the organisations in our study were diverse in their geography and socio-economic indicators; and they varied greatly in the number and variety of the features of transitional healthcare that they offered. ${ }^{34}$

\section{Conclusion}

Our research provides new insight into how transitional healthcare could be improved for young people with long-term conditions. The implications are based on the evidence from the Transition research programme and are not restricted to either specific disorders or particular specialist services. With this in mind, we consider that the findings are relevant to international audiences and a broad range of stakeholders including commissioners of transitional healthcare, managers of transitional healthcare at the level of a provider organisation, and to clinical practitioners working with young people in both children's and adults' healthcare settings.

\section{Acknowledgements}

We acknowledge the support of the NIHR Clinical Research Network. Dr McDonagh was supported by the NIHR Manchester Biomedical Research Centre.

We thank the members of the Young Persons' Advisory Group (UP) for their work throughout the study. We thank the members of the external advisory board, which included a parent with a son and daughter with long-term conditions, representatives of two patient organisations and members of the UP group.

We thank the research assistants: Kam Ameen-Ali, Sarah Balne, Shaunak Deshpande, Louise Foster, Charlotte George, Albert Farre, Michaela Fay, Louisa Fear, Kate Hardenberg, Jenni Hislop, Guio Garcia Jalon, Niina Kolemainen, Kay Mann, Helen Mason, Sara McCafferty, Hannah Merrick, Holly Roper, Tracy Scott, Catherine Sheppard, Louise Ting, Rose Watson, Hazel Windmill and Victoria Wood.
The Transition Collaborative Group consists of the authors of this paper and Amanda Billson, Anastasia Bem, Stuart Bennett, Stephen Bruce, Tim Cheetham, Diana Howlett, Zilla Huma; Mark Linden, Maria Lohan, Cara Maiden, Melanie Meek, Jenny Milne, Julie Owens, Jackie Parkes, Fiona Regan and Nandu Thalange.

\section{References}

1 Royal College of Paediatrics and Child Health. Facing the future: standards for children with ongoing health needs. London: RCPCH, 2018. www.rcpch.ac.uk/sites/default/files/2018-04/ facing_the_future_standards_for_children_with_ongoing_health_ needs_2018-03.pdf [Accessed 16 May 2019].

2 Royal College of Physicians. On the margins of medical care: Why young adults and adolescents need better healthcare. London: RCP, 2015.

3 Gleeson H. Guidance on training in adolescent and young adult health care (including transition). London: Joint Royal Colleges of Physicians Training Board, 2018.

4 Queiros FC, Wehby GL, Halpern CT. Developmental disabilities and socioeconomic outcomes in young adulthood. Public Health Rep 2015;130:213-21.

5 Pinquart M. Achievement of developmental milestones in emerging and young adults with and without pediatric chronic illness - a meta-analysis. J Pediatr Psychol 2014;39:577-87.

6 Maslow GR, Haydon A, McRee AL, Ford CA, Halpern CT. Growing up with a chronic illness: social success, educational/vocational distress. J Adolesc Health 2011;49:206-12.

7 Miller KM, Foster NC, Beck RW et al. Current state of type 1 diabetes treatment in the U.S.: updated data from the T1D Exchange clinic registry. Diabetes Care 2015;38:971-8.

8 Clements MA, Foster NC, Maahs DM et al. Hemoglobin A1c ( $\mathrm{HbA1C}$ ) changes over time among adolescent and young adult participants in the T1D exchange clinic registry. Pediatr Diabetes 2016;17:327-36.

9 Solanke F, Colver A, McConachie H. Are the health needs of young people with cerebral palsy met during transition from child to adult health care? Child Care Health Dev 2018;44:355-63.

10 Taylor JL, Seltzer MM. Employment and post-secondary educational activities for young adults with autism spectrum disorders during the transition to adulthood. J Autism Dev Disord 2011:41:566-74.

11 Hendricks DR, Wehman P. Transition From school to adulthood for youth with autism spectrum disorders. Focus on Autism and Other Developmental Disabilities 2009;24:77-88.

12 Davies SC. Annual report of the chief medical officer 2012: Our children deserve better: prevention pays. London: Department of Health, 2013.

13 Grant C, Pan J. A comparison of five transition programmes for youth with chronic illness in Canada. Child Care Health Dev 2011;37:815-20.

14 American Academy of Pediatrics, American Academy of Family Physicians, American College of Physicians et al. Supporting the health care transition from adolescence to adulthood in the medical home. Pediatrics 2011;128:182-200.

15 Blum RW, Garell D, Hodgman CH et al. Transition from childcentered to adult health-care systems for adolescents with chronic conditions. A position paper of the Society for Adolescent Medicine. J Adolesc Health 1993;14:570-6.

16 World Health Organization. Young people: health risks and solutions. Fact sheet N³45. Geneva: WHO, 2011. http://www.who.int/ mediacentre/factsheets/fs345/en/\# [Accessed 25 August 2018].

17 Department of Health. Transition: getting it right for young people: Improving the transition of young people with long term conditions from children's to adult health services. London: DoH, 2006.

18 National Institute for Health and Care Excellence. Transition from children's to adults' services for young people using health or social care services. London: NICE, 2016. 
19 Hepburn CM, Cohen E, Bhawra J et al. Health system strategies supporting transition to adult care. Arch Dis Child 2015;100: 559-64.

20 Mazur A, Dembinski L, Schrier L, Hadjipanayis A, Michaud PA. European Academy of Paediatrics consensus statement on successful transition from paediatric to adult care for adolescents with chronic conditions. Acta Paediatr 2017;106:1354-7.

21 Watson R, Parr J, Joyce C, May C, Le Couteur A. Models of healthcare transition for young people with complex health needs: a scoping review. Child Care Health Dev 2011;37:780-91.

22 Campbell F, Biggs K, Aldiss S et al. Transition of care for adolescents from paediatric services to adult health services. Cochrane Database Syst Rev 2016:4:CD009794.

23 Colver A, Rapley T, Parr JR et al. Facilitating the transition of young people with long-term conditions through health services from childhood to adulthood: the Transition research programme. Programme Grants Appl Res 2019;7.

24 Maniatopoulos G, Le Couteur A, Vale L, Colver A. Falling through the gaps: exploring the role of integrated commissioning in improving transition from children's to adults' services for young people with long-term health conditions in England. J Health Serv Res Policy 2018;23:107-15.

25 Sawyer SM, Afifi RA, Bearinger LH et al. Adolescence: a foundation for future health. Lancet 2012:379:1630-40.

26 Colver A, Longwell S. New understanding of adolescent brain development: relevance to transitional healthcare for young people with long term conditions. Arch Dis Child 2013;98:902-7.

27 Farre A, Wood V, McDonagh JE et al. Health professionals' and managers' definitions of developmentally appropriate healthcare for young people: conceptual dimensions and embedded controversies. Arch Dis Child 2016;101:628-33.

28 Farre A, Wood V, Rapley T et al. Developmentally appropriate healthcare for young people: a scoping study. Arch Dis Child 2015;100:144-51.

29 Northumbria Healthcare NHS Foundation Trust. Developmentally Appropriate Healthcare Toolkit: A toolkit to support delivery of "Developmentally Appropriate Healthcare" in the NHS. Northumbria Healthcare NHS Foundation Trust, 2017. www.northumbria.nhs.uk/quality-and-safety/clinical-trials/forhealthcare-professionals [Accessed 01 November 2019].

30 Farre A, McDonagh JE. Helping health services to meet the needs of young people with chronic conditions: towards a developmental model for transition. Healthcare (Basel) 2017;5:77.

31 McDonagh JE, Farre A, Gleeson $\mathrm{H}$ et al. Making healthcare work for young people. Arch Dis Child 2018;103:623.

32 Colver AF, Merrick H, Deverill M et al. Study protocol: Longitudinal study of the transition of young people with complex health needs from child to adult health services. BMC Public Health 2013;13:675

33 Colver A, McConachie H, Le Couteur A et al. A longitudinal, observational study of the features of transitional healthcare associated with better outcomes for young people with long-term conditions. BMC Med 2018;16:111.

34 Colver A, Pearse R, Watson RM et al. How well do services for young people with long term conditions deliver features proposed to improve transition? BMC Health Serv Res 2018;18:337.

35 Allen D, Channon S, Lowes L, Atwell C, Lane C. Behind the scenes: the changing roles of parents in the transition from child to adult diabetes service. Diabet Med 2011;28:994-1000.

36 Heath G, Farre A, Shaw K. Parenting a child with chronic illness as they transition into adulthood: A systematic review and thematic synthesis of parents' experiences. Patient Educ Couns 2017;100:76-92.

37 Sattoe JN, Bal MI, Roelofs PD et al. Self-management interventions for young people with chronic conditions: A systematic overview. Patient Educ Couns 2015;98:704-15.

38 Channon SJ, Huws-Thomas MV, Rollnick S et al. A multicenter randomized controlled trial of motivational interviewing in teenagers with diabetes. Diabetes Care 2007;30:1390-5.

39 Harden PN, Walsh G, Bandler N et al. Bridging the gap: an integrated paediatric to adult clinical service for young adults with kidney failure. BMJ 2012;344:e3718.

40 Hislop J, Mason H, Parr JR, Vale L, Colver A. Views of young people with chronic conditions on transition from pediatric to adult health services. J Adolesc Health 2016:59:345-53.

41 Suris JC, Akre C. Key elements for, and indicators of, a successful transition: an international Delphi study. J Adolesc Health 2015;56:612-8.

42 Prior M, McManus M, White P, Davidson L. Measuring the 'triple aim' in transition care: a systematic review. Pediatrics 2014;134:e1648-61.

43 World Health Organization. International Classification of Functioning, Disability and Health: Children and Youth Version: ICF-CY. Geneva: WHO, 2007.

44 Scal P. Improving health care transition services: just grow up, will you please. JAMA Pediatr 2016;170:197-9.

45 Fair C, Cuttance J, Sharma $\mathrm{N}$ et al. International and Interdisciplinary Identification of health care transition outcomes. JAMA Pediatr 2016;170:205-11.

46 Askew K, Bamford J, Hudson N et al. Current characteristics, challenges and coping strategies of young people with cystic fibrosis as they transition to adulthood. Clin Med 2017;17:121-5.

47 Shalaby MS, Gibson A, Granitsiotis P, Conn G, Cascio S. Assessment of the introduction of an adolescent transition urology clinic using a validated questionnaire. J Pediatr Urol 2015;11:89.e1-5.

Address for correspondence: Prof Allan Colver, Newcastle University, James Spence Building, Newcastle upon Tyne NE1 4LP, UK.

Email: allan.colver@ncl.ac.uk 